\title{
Resenha do livro EDMONDSON, Ray. Filosofia e princípios da arquivística audiovisual. Trad. Carlos Roberto de Souza. Rio de Janeiro: Associação Brasileira de Preservação Audiovisual/Cinemateca do Museu de Arte Moderna do Rio de Janeiro, 2013. 224p.
}

Fabián Núñez*

\begin{abstract}
RESENHA
A tradução da obra de Edmondson cumpre um importante papel no Brasil, carente de publicações em Português na área de preservação audiovisual. Foi movida por esse propósito que a Associação Brasileira de Preservação Audiovisual (ABPA) optou por esse texto para iniciar as suas publicações. Poderíamos dizer que se trata de um livro de referência, desde a sua concepção. Editado sob os auspícios da UNESCO e da CCAAA ${ }^{1}$, seu objetivo é assentar as bases de uma reflexão específica para um campo subestimado do ponto de vista teórico, tanto pelos estudos de audiovisual quanto pela ciência da informação. Originalmente publicado em 1998, ganhou uma segunda edição revista e ampliada em 2004. Ray Edmondson é, atualmente, um dos principais nomes da arquivística audiovisual, área na qual trabalha desde 1968, tornando-se diretor-adjunto da National Film and Sound Archive da Austrália, desde a sua fundação em 1984 até 2001. Graças a seu importante papel na área, tanto na ação institucional quanto no campo teórico, atua junto à UNESCO e a outras entidades internacionais.
\end{abstract}

O livro é dividido em sete capítulos (Introdução; Fundamentos; Definição e Terminologia; Arquivos Audiovisuais; Preservação: características e conceitos; Princípios de gestão e Ética - além da Conclusão), organizados em subcapítulos, com parágrafos numerados, o que auxilia uma leitura objetiva de acordo com a intenção de ser uma referência teórica. É justamente por essa vocação que a obra foi selecionada pela ABPA, pois visa, acima de tudo, estabelecer conceitos e definições para uma área desprovida, até então, de reflexão teórica. Como frisa o autor, ao longo do século passado, a arquivística audiovisual se consolidou de modo empírico, baseando-se em outras disciplinas e seguindo tradicionalmente uma divisão por produção ou mídia. Esse é um ponto fundamental, uma vez que o teórico australiano considera o profissional que atua em um arquivo audiovisual como uma "profissão de direito próprio", independentemente de reconhecimento oficial e/ou acadêmico mundo afora. Em suma, não se trata, em seus termos, de um "subconjunto especializado de uma profissão já existente", como outras profissões relacionadas à arquivística clássica, embora esteja intrinsecamente relacionada com elas.

\footnotetext{
* Universidade Federal Fluminense (UFF), Doutor em Comunicação. Endereço profissional: Rua Prof. Lara Vilela, 126 - São Domingos. CEP 24210-590. Niterói-RJ. Telefone: (21) 2629-9761

${ }^{1}$ Co-ordinating Council of Audiovisual Archives Associations, fórum internacional que reúne as principais associações da arquivística audiovisual.
} 
Concordamos que se trata de um tema polêmico, que pode suscitar debates e ferir sensibilidades, mas essa discussão lançada por Edmondson, logo no início do livro, torna-se chave quando ele aborda, no final da obra, os aspectos éticos dessa profissão "não formalizada". Ao discutir os princípios básicos que norteiam a preservação dos documentos audiovisuais, Edmondson reconhece a existência de um grupo de profissionais que apesar de, em geral, possuírem formações diversas e atuarem em instituições semelhantes, mas não encaradas como sinônimas, compartilham entre si um conhecimento e um conjunto de práticas, o que os torna profissionais de um mesmo campo. Um dos pontos mais importantes desse tópico é a dimensão ética que permeia esse savoir-faire, postulando a vocação por uma área como um fundamento-chave desse profissional e assim desviando-se dos corporativismos tão paradoxalmente atuais em tempos em que a "multidisciplinaridade" é tão entoada. Também por esse viés, podemos entender a advertência de Edmondson na Conclusão, ao chamar a atenção para o grau de importância que os documentos audiovisuais têm há pouco mais de cem anos, apesar de esses acervos estarem nas mãos de algumas instituições e poucos profissionais, o que é um sintoma da frágil compreensão da relevância da área aos olhos da sociedade, incluindo não apenas a classe política mas, muitas vezes, os profissionais do próprio setor audiovisual.

Portanto, o entendimento de Edmondson, ao postular a "arquivística audiovisual" como uma profissão própria, é compreender a singularidade do campo, cujo conhecimento é construído de modo interdisciplinar. Para isso, Edmondson frisa a amplitude do conceito "audiovisual", que não se restringe ao que o senso comum entende, mas a todo tipo de produção de imagens em movimento e sons gravados. ${ }^{2}$ Assim, apesar de tradicionalmente os arquivos audiovisuais terem se diferenciado por tipo de produção ou mídia (cinematecas, arquivos de televisão, arquivos de documentos sonoros, museus de dispositivos audiovisuais, como museus de cinema ou de videogames, além de setores especializados em arquivos gerais, bibliotecas ou museus), Edmondson compreende a todos como partícipes de uma mesma atividade: a "arquivística audiovisual". Logo, é necessário buscar uma definição de "arquivo audiovisual".

Buscando evitar categorizações apriorísticas, o autor parte da seguinte definição: “o arquivo audiovisual é uma organização ou um departamento de uma organização cuja missão, eventualmente estabelecida por lei, consiste em facilitar o acesso a uma coleção de documentos audiovisuais e ao patrimônio audiovisual mediante atividades de reunião, gestão, conservação e promoção." Portanto, como o próprio autor indica, as quatro atividades citadas devem ser entendidas como as funções principais de um arquivo audiovisual, i.e., um arquivo audiovisual não deve fazer uma ou duas dessas funções, mas necessária e simultaneamente todas as quatro (ou pelo menos visar praticá-las) como sua missão institucional. Logo, um setor de empréstimo de mídias audiovisuais em uma biblioteca, por exemplo, não entra nessa definição, uma vez que tal entidade não possui como fim último garantir a preservação de documentos audiovisuais (o que significa também atividades de conservação e salvaguarda, o que inclui, entre outras ações, o restauro). No entanto, como Edmondson frisa, não se trata de uma definição categórica, uma vez que determinados acervos audiovisuais podem mudar no decorrer do tempo a sua missão

\footnotetext{
${ }^{2}$ Edmondson toma como referência conceitual a Recomendação para a salvaguarda e preservação das imagens em movimento, aprovada na XXI Conferência-Geral da UNESCO, em 1980. É o primeiro documento internacional sobre preservação audiovisual.
} 
institucional, vindo a abarcar todas as quatro funções mencionadas. Por conseguinte, torna-se importante buscar entender o que é "preservação audiovisual".

Assim, a definição de arquivo audiovisual, postulada anteriormente, está em consonância com o entendimento de que a "preservação não é um fim em si". Tratase de um conjunto de critérios e operações, posto em prática de modo sistemático e perene, cujo objetivo último é garantir o acesso permanente aos documentos audiovisuais no máximo grau de sua integridade. Por conseguinte, a preservação (entendida em seu sentido estrito, i.e., conservação e restauração) e o acesso são "duas faces de uma mesma moeda", pois são atividades interdependentes e complementares, inerentes ao arquivo audiovisual. Nesse aspecto, o teórico australiano frisa o falso problema que, muitas vezes, vemos na história das instituições de guarda, causado pelo dilema entre preservação e acesso. Desse modo, partindo da ideia da garantia do acesso permanente, Edmondson se junta a outros teóricos da área de preservação audiovisual, frisando que esta é a manutenção, a longo prazo, dos documentos audiovisuais, o que significa que "nunca se termina de preservar uma obra; na melhor das hipóteses, ela está sempre em processo de preservação".

Portanto, ao postular tais princípios, Edmondson passa a definir os critérios que regem a gestão dos documentos audiovisuais, como o conceito de obra individual como unidade básica de catalogação, o que aproxima, nesse aspecto, a arquivística audiovisual da biblioteconomia. $O$ autor também analisa vários aspectos comuns aos arquivos audiovisuais, como a questão da obsolescência técnica, fantasma que ronda a área, já que uma das singularidades dos documentos audiovisuais é o acesso à informação apenas por intermediação tecnológica. E isso significa não somente a conservação dos suportes mas também de seus dispositivos. Nesse ponto, Edmondson chama a atenção para a relevância do fator humano em um arquivo, pois tais instituições tendem a perder a expertise sobre equipamentos obsoletos ou em obsolescência, caso não haja uma política de transmissão de conhecimento. Como frisa o autor, a obsolescência tecnológica é uma velha conhecida dos arquivos audiovisuais, muito antes de esse terror se espalhar no âmbito arquivístico em geral com o digital. Sobre esse último tópico, embora não seja um especialista no tema, Edmondson tece interessantes considerações, sobretudo ao sublinhar a maior evidência dos arquivos frente à sociedade, justamente por conta da transição para o digital.

Frisamos que o livro de Edmondson retrata muito bem o cotidiano em um arquivo audiovisual, não somente ao abordar a atualidade da questão sobre o "dilema digital", mas em muitos outros aspectos, que se vinculam, em última instância, com a constante ausência de políticas públicas em preservação audiovisual. Nesse sentido, o leitor percebe que, infelizmente, a realidade dos arquivos audiovisuais é bastante semelhante, seja na Oceania ou na América Latina. E é por esse viés que entendemos o capítulo sobre a ética profissional e a Conclusão, tornando legível nas entrelinhas uma das principais lições de Edmondson, em seus mais de quarenta e cinco anos dedicados à arquivística audiovisual: a sociedade legou ao arquivista audiovisual uma imensa responsabilidade, já que o esforço de manter a memória audiovisual possui como diametralmente oposta a vontade em deturpá-la e destruíla. Movido pela vocação e por um inabalável fundamento ético, esse profissional, apesar de

\footnotetext{
3 Para uma análise do conceito de "preservação audiovisual", sugerimos a tese de doutorado de Carlos Roberto de Souza, tradutor do livro analisado nesta Resenha.
} 
tradicionalmente ser uma figura arredia aos holofotes (como em geral são os profissionais da ciência da informação), deve vir à cena pública, respaldado por um saber consolidado que deve ser respeitado e como cidadão, para chamar a atenção da sociedade para a preservação do patrimônio audiovisual. Portanto, além de ser um incontornável livro teórico, a obra de Edmondson é fundamentalmente um ato político.

Artigo recebido em 07/07/2014 e aprovado em 29/07/2014 